Research article

\title{
Morphology, molecular identification and phylogenetic analysis based on internal transcribed spacer (ITS) of the ribosomal nuclear DNA (rDNA) sequence of a pathogenic fungal isolate Aspergillus niger LKO1
}

\author{
Maneesha George and Pramod W. Ramteke* \\ Sam Higginbottom University of Agriculture, Technology and Sciences, Post Agricultural Institute, Rewa Road, \\ Naini, Prayagraj-211007, Uttar Pradesh, India
}

*Corresponding Author: pramod.ramteke@shiats.edu.in

[Accepted: 19 June 2019]

\begin{abstract}
Aspergillus niger is the causal organism of "black mold" disease of fruits and vegetables. The objective of the present investigation was to characterize the pathogen morphologically in vitro and to confirm its molecular identity and phylogenetic position by the sequence of ITS region of rDNA. A. niger LKO1 was isolated from soil and cultured in PDB and PDA media. The characteristic of growth was monitored and the reproductive structures were analyzed. After 3 days of growth, the diameter of each colony was $1.5 \mathrm{~cm}$, after which the colony was extended its diameter $1 \mathrm{~cm}$ per day and subsequently black conidiophores were formed with black pigmented spore heads carrying numerous conidia. Fungus was also characterized using molecular methods based on ITS-PCR (GenBank accession number MK696283). The amplified sequence was compared with the available sequences in the NCBI GenBank. The sequence showed $100 \%$ similarity with other isolates of A. niger. The isolation, morphological characterization and sequencing of ITS region of rDNA will help in further research on the management of this plant pathogen and its commercial utilization.
\end{abstract}

Keywords: Aspergillus niger - ITS sequence - Morphological characteristics - Plant pathogen.

[Cite as: George M \& Ramteke PW (2019) Morphology, molecular identification and phylogenetic analysis based on internal transcribed spacer (ITS) of the ribosomal nuclear DNA (rDNA) sequence of a pathogenic fungal isolate Aspergillus niger LKO1. Tropical Plant Research 6(2): 166-170]

\section{INTRODUCTION}

Aspergillus is the most abundant pathogenic fungus worldwide, which comprises of more than 837 species (Hawksworth 2011). They frequently cause the invasive allergic infections in humans such as bronchopulmonary diseases, mycotic keratitis, otomycosis, nasal sinusitis etc. Pitt \& Hocking (1997) stated that Aspergillus niger van Tieghem is the most common species of Aspergillus. It was first described in 1867 in a manuscript entitled "Physiologie des mucédinées" by the French botanist Philippe (Dijksterhuis \& Wösten 2013). He isolated this fungus from molded galls with the main aim to study the production of gallic acid by a process of fungal fermentation. It is a cosmopolitan fungus not very selective with respect to the environmental conditions. It thrives in the soil and on decaying plant material but is also abundant in man-made environments. It can be found on the floor, in carpet and mattress dust (Flannigan et al. 2011). It grows between temperature of 6 and $47^{\circ} \mathrm{C}$, pH 1.5 and 9.8 (Pitt \& Hocking 2009).

Initially it has been reported as a pathogen of Zingiber officinale Roscoe plants (Pawar et al. 2008). Generally, it causes "black mold" disease in certain fruits, vegetables and food products such as onions, rice, coffee, nuts etc. It is responsible for post-harvest decay of guava, litchis, mangoes, papaya, pineapples, pomegranates, apples, pears, and grapes. During colonization, it may produce the mycotoxins ochratoxin A and fumonisins. Beside this Aspergillus niger has several beneficial applications. It is used for waste management and biotransformations. It is also used as a cell factory for the production of enzymes. These enzymes are used in a wide variety of applications ranging from clarification of fruit juices, lipid hydrolysis during cheese 
production, and degradation of phytate in animal feeds (Wösten et al. 2007). It is also widely used for the production of the food additives citric acid and gluconic acid. It produces large amounts of citric acid in a medium containing sugar (Currie 1917). It is the major source of citric acid; this organism accounts for over 99\% of global citric acid production, or more than 1.4 million tonnes per year (Papagianni \& Mattey 2006).

Proper identification of pathogenic fungus is very important to treat the diseased plants (Henry et al. 2000). Generally identification of the Aspergillus species is carried out by microscopic examination of the morphological characteristics of the colony. However, taxonomists faced the problems due to different hyphal thickness, similar sexual structures and sometimes lack of sexual structures (Henry et al. 2000). Although, molecular methods are more accurate quick and easy and thus became essential tools for identification of fungus (Henry et al. 2000, Shittu et al. 2016).

In the present study, we have isolated the fungal pathogen Aspergillus niger. We have identified the pathogen morphologically based on its vegetative and reproductive structures. We have also obtained the sequence of the internal transcribed spacer (ITS) of the ribosomal nuclear DNA (rDNA) with the PCR method using universal primers (Chen et al. 1992) for the molecular identification and phylogenetic analysis and sequence has been deposited in GenBank (NCBI).

\section{MATERIALS AND METHODS}

Collection and isolation of the fungus

The sample was collected from soil samples in sterile capped bottles from Lucknow $\left(26^{\circ} 5^{\prime} \mathrm{N}\right.$ latitude, $80^{\circ}$ $56^{\prime}$ E longitude), the capital of Uttar Pradesh. The collected sample was purified in sterile distilled water and maintained on PDB (potato dextrose broth) and solid media like PDA (potato dextrose agar) at $25^{\circ} \mathrm{C}$ (Booth 1971). The isolate was identified with the help of keys provided by (Raper \& Fennell 1965, Samson \& Varga 2007, Bennett 2010) and also by sequence obtained from ITS-PCR.

\section{DNA isolation and PCR}

The microorganism was aseptically transferred from stock-culture into tubes containing inclined potato dextrose agar medium PDA obtained from Himedia Laboratories (India). The inoculated tubes were incubated at $30^{\circ} \mathrm{C}$ for 7 days and were conserved at $4{ }^{\circ} \mathrm{C}$. A $0.3 \%$ sterile solution of Tween 80 was added to a tube containing activation culture. Spores were manually removed by the platinum loop from the agar surface. A sample of 0.1 $\mathrm{ml}$ of the suspension was transferred to $90 \mathrm{~mm}$ Petri dishes containing PDA. Media were incubated in the dark at $30^{\circ} \mathrm{C}$ for 10 days.

The mycelium was then washed in TE buffer (10 mM Tris- $\mathrm{HCl} \mathrm{pH} 8,1 \mathrm{mM}$ EDTA) and was kept at $320^{\circ} \mathrm{C}$ for $24 \mathrm{hrs}$ and DNA was extracted. Polymerase chain reactions were performed in $50 \mu \mathrm{l}$ volumes containing 100 pmol of each of the universal primers ITS1 (TCC GTA GGT GAA CCT GCG G) and ITS4 (TCC TCC GCT TAT TGA TAT GC); $200 \mu \mathrm{M}$ of each of the four dNTPs; $1.5 \mathrm{U}$ of Taq polymerase (Invitrogen) and $300 \mathrm{ng}$ DNA template in a PCR buffer $(50 \mathrm{mM} \mathrm{KCl}, 1.5 \mathrm{mM} \mathrm{MgCl} 2,10 \mathrm{mM}$ Tris-HCl). The temperature cycling parameters were $95^{\circ} \mathrm{C}$ for $3 \mathrm{~min}$ for denaturation of the first cycle and $1 \mathrm{~min}$ for subsequent cycles, primer annealing for $1 \mathrm{~min}$ at $55^{\circ} \mathrm{C}$ and primer extension at $72^{\circ} \mathrm{C}$ for $1 \mathrm{~min}$ with a total of 35 cycles and a final extension at $72^{\circ} \mathrm{C}$ for $3 \mathrm{~min}$. The sequence of the ITS region of the rDNA has been deposited at the GenBank (NCBI).

\section{Sequencing and phylogenetic analysis}

The PCR product was purified and sequenced (Chromous Biotech Pvt. Ltd., Bangalore). The sequence was compiled by ApE software (A plasmid Editor). The rDNA sequence was submitted to NCBI GeneBank. The sequence was also blasted (NCBI) to determine the percentage of similarity with related sequences. The BioEdit sequence alignment editor was used to obtain multiple alignments of nucleotides with related sequences for ITS. The blast output was processed for generating the phylogenetic tree in software MEGA7 by using 'Maximum Likelihood' method based on the Tamura-Nei model (Tamura \& Nei 1993, Kumar et al. 2016).

\section{RESULTS AND DISCUSSION}

Growth, macroscopic features of colonies and microscopic characters for identification

Dormant conidia ( $3.5 \mu \mathrm{m}$ mean diameter) were increased in diameter of $4.0 \mu \mathrm{m}$ in deionized water and in the PDB swelled to 6.5 to $7.0 \mu \mathrm{m}$ before germ-tube outgrowth. The majority of conidia produced one or occasionally two germ tubes between 6 and $9 \mathrm{~h}$ after incubation at $30^{\circ} \mathrm{C}$. The hyphae within the mycelium were divided by septa. After 3 days of growth, the diameter of each colony was $1.5 \mathrm{~cm}$, after which the colonies were extended its diameter $1 \mathrm{~cm}$ per day. The diameter of each colony was $5 \mathrm{~cm}$ after 7 days of growth. Five 
concentric zones were arbitrarily distinguished in the sandwiched colony. After vegetative growth it was produced conidiophores (the asexual reproductive structures). Previously, Levin et al. (2007) assessed the effect of substrate heterogeneity in colonies of A. niger. de Farias et al. (2010) compared the spore production in different media.

Macroscopically, white colonies were visible on agar surfaces and occasionally developed yellow tinges on which subsequently black conidiophores were formed. With a binocular, slender stalks bearing small white spherical vesicles that mature into black pigmented spore heads carrying numerous conidia on phialides and metulae have been observed. The round vesicles and the pronounced metulae can be regarded as a hallmark for A. niger. Recently, maturation of conidia on these asexual reproductive structures was studied by Teertstra et al. (2017). He found that pigmented conidia that had developed on conidiophores for 2, 5, and 8 days were resistant to heat.

Microscopic morphology of A. niger LKO1 showed large, globose, black conidial heads, which became radiate, tending to split into several loose columns with age. Conidiophores were smooth-walled, hyaline or turning dark towards the vesicle. Conidial heads were biseriate with the phialides born on brown, often septate metulae. Conidia were globose to subglobose, black and rough-walled (Fig. 1). The ability of conidia to produce conidiophores after germination depends on temperature and nutrients provided in the medium (Anderson \& Smith 1971).

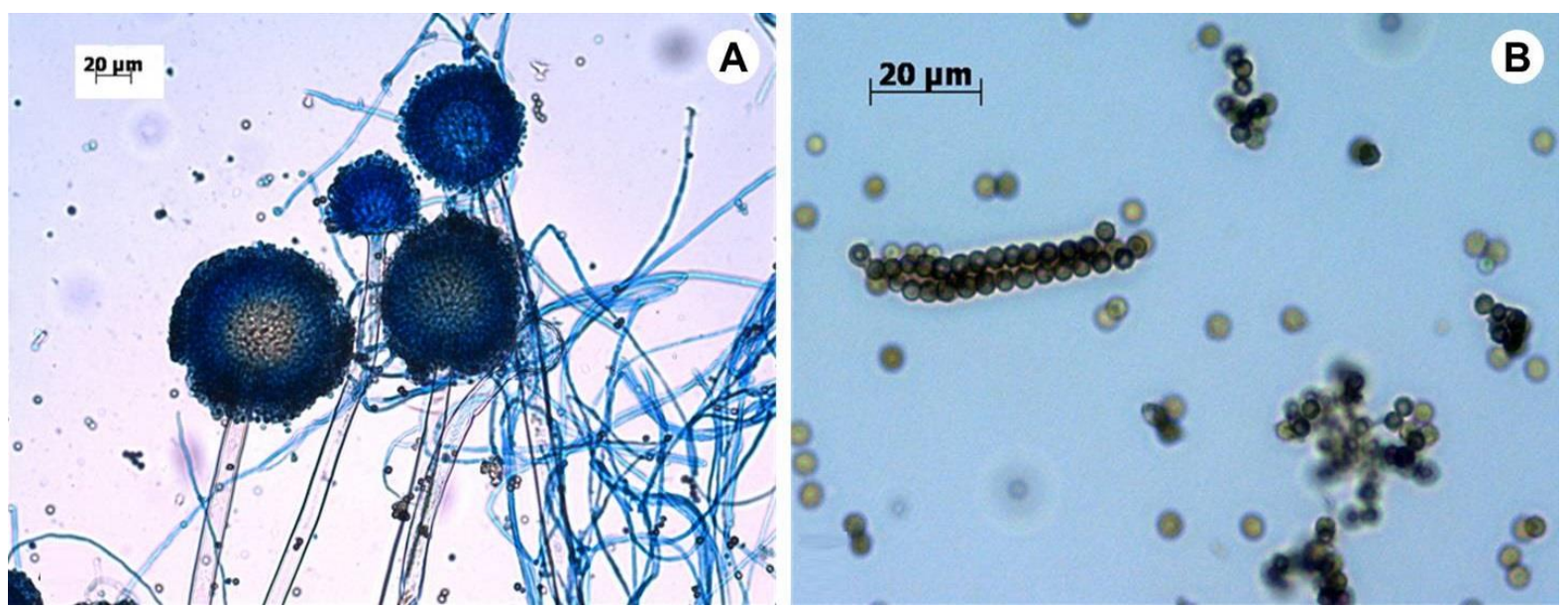

Figure 1. Vegetative and asexual reproductive structures of Aspergillus niger: A, Mycelia with conidiophores; B, Condia.

Molecular identification based on the sequence of ITS region of rDNA

In the present study, the partial ITS sequence of the flanking regions of the ribosomal nuclear DNA of $A$. niger LKO1 was PCR amplified using the specific forward and reverse primers with an amplicon size 541 base pairs. Sequence was submitted to NCBI GenBank (Accession number MK696283). Sequence of amplified ITS region was given below.

1 ccatccgtgt ctattatacc ctgttgettc ggegggeccg ccgettgtcg gecgecgggg

61 gggcgecttt geccccggg cccgtgcceg ccggagaccc caacacgaac actgtctgaa

121 agcgtgcagt ctgagttgat tgaatgcaat cagttaaaac tttcaacaat ggatctcttg

181 gttccggcat cgatgaagaa cgcagcgaaa tgcgataact aatgtgaatt gcagaattca

241 gtgaatcatc gagtctttga acgcacattg cgcccctgg tattccgggg ggcatgcctg

301 tccgagcgtc attgctgcce tcaagccegg cttgtgtgtt gggtcgecgt cccctctcc

361 ggggggacgg gcccgaaagg cagcggcggc accgcgtccg atcctcgagc gtatgggget

421 ttgtcacatg ctctgtagga ttggccggcg cetgccgacg ttttccaacc atttttcca

481 ggttgacctc ggatcaggta gggatacccg ctgaacttaa gcatatcaat aaggcggggg

The amplified sequence was blasted in the NCBI. The sequence showed $100 \%$ similarity to partial sequence of internal transcribed spacer 1 (ITS 1) of 5.8S ribosomal RNA gene and internal transcribed spacer 2 (ITS 2) of large subunit ribosomal RNA gene with 4 sequences of A. niger (HM210842.1, EF134625.1, KT876702.1 and KP794197.1) and 99\% similarity with other isolates of A. niger (MH055393.1, MH345876.1, MG759551.1 etc.) as well as with A. tubingensis (MH345877.1, MH055396.1, MG659603.1 etc.). Phylogenetic tree constructed from the blast result of NCBI also showed that the fungus is closer to both the fungus (Fig. 2A). However, 
Taxonomic analysis based on NCBI GenBank database confirmed the fungus as a member of Ascomycetes (97 hits) and maximum similarity of sequence was matched with A. niger (53 hits) (Fig. 2B).

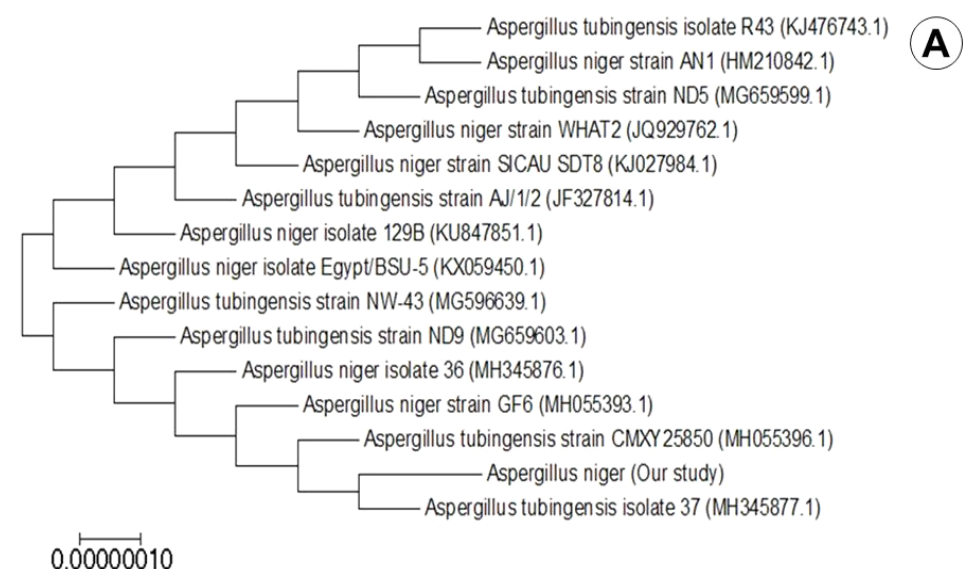

igure 2. A, Molecular Phylogenetic analysis of Aspergillus niger based on the Tamura-Nei model by Maximum Likelihood method. The analysis is based on 14 nucleotide sequences from NCBI BLAST result; B, Taxonomic analysis based on NCBI GenBank database confirmed the fungus as a member of Ascomycetes (97 hits) and maximum similarity of sequence was matched with A. niger (53 hits).

In earlier studies, Henry et al. (2000) successfully identified 11 clinical isolates of Aspergillus from ITS amplicons ranged in size from 565 to 613 bp. Both ITS 1 and ITS 2 regions were needed for accurate identification of Aspergillus at the species level (Henry et al. 2000, Shittu et al. 2016).

\section{CONCLUSION}

The causal organism of "black mold" disease of fruits and vegetables, Aspergillus niger LKO1 was isolated from Lucknow, India. The taxonomic identification was carried out by morphological diagnosis and molecular analysis. After the analysis of characteristics and dimensions of hyphae, conidiophores and conidia fungus was identified as A. niger. ITS sequence showed the $100 \%$ similarity (NCBI) with other isolates of A. niger. Phylogenetic analysis was revealed the Maximum Likelihood with two Aspergillus species A. niger and A. tubingensis. However, Taxonomic analysis based on NCBI GenBank database confirmed the fungus as A. niger, a member of Ascomycetes. The isolation and identification of this fungus will help in further research on accurate biological control for this plant pathogen and its commercial utilization.

\section{ACKNOWLEDGMENTS}

Authors are grateful to Sam Higginbottom University of Agriculture, Technology and Sciences, Post Agricultural Institute of Prayagraj, Uttar Pradesh for thorough support to carry out the work.

\section{REFERENCES}

Anderson JG \& Smith JE (1971) The production of conidiophores and conidia by newly germinated conidia of Aspergillus niger (microcycle conidiation). Microbiology 69(2): 185-197.

Bennett JW (2010) An overview of the genus Aspergillus. In: Aspergillus: molecular biology and genomics. Caister Academic Press, pp. 1-17.

Booth C (1971) Fungal Culture Media. In: Methods in microbiology, Vol. 4. Academic Press, pp. 49-94.

Chen J, Moinard M, Xu J, Wang S, Foulongne-Oriol M, Zhao R, Hyde KD \& Callac P (1992) Taxonomic and phylogenetic analyses of ten Pythium species using isozyme polymorphisms. Phytopathology 82: 12341244.

Currie JN (1917) The citric acid fermentation of Aspergillus niger. Journal of Biological Chemistry 31: 15-37.

de Farias VL, Monteiro KX, Rodrigues S, Fernandes FAN \& Pinto GAS (2010) Comparison of Aspergillus niger spore production on Potato Dextrose Agar (PDA) and crushed corncob medium. Journal of General and Applied Microbiology 56(5): 399-402.

Dijksterhuis J \& Wösten (2013) Development of Aspergillus niger. In: Studies in mycology. No: 74 0166-0616. CBS-KNAW Fungal Biodiversity Centre, Utrecht, Netherlands.

Flannigan B, Samson RA \& Miller JD (2011) Microorganisms in home and indoor work environments. In: Diversity, health impacts, investigation and control, $2^{\text {nd }}$ Edition. Taylor and Francis, Boca Raton, pp. 539.

Hawksworth DL (2011) Naming Aspergillus species: progress towards one name for each species. Medical Mycology 49: S70-S76.

www.tropicalplantresearch.com 
Henry T, Iwen PC \& Hinrichs SH (2000) Identification of Aspergillus species using internal transcribed spacer regions 1 and 2. Journal of Clinical Microbiology 38(4): 1510-1515.

Kumar S, Stecher G \& Tamura K (2016) MEGA7: Molecular Evolutionary Genetics Analysis version 7.0 for bigger datasets. Molecular Biology and Evolution 33: 1870-1874.

Levin AM, de Vries RP, Conesa A, de Bekker C, Talon M, Menke HH, van Peij NN \& Wösten HA (2007) Spatial differentiation in the vegetative mycelium of Aspergillus niger. Eukaryot Cell 6(12): 2311-2322.

Papagianni M \& Mattey M (2006) Morphological development of Aspergillus niger in submerged citric acid fermentation as a function of the spore inoculum level. Application of neural network and cluster analysis for characterization of mycelial morphology. Microbial Cell Factories 5(1): 3.

Pawar NV, Patil VB, Kamble SS \& Dixit GB (2008) First Report of Aspergillus niger as a Plant Pathogen on Zingiber officinale from India. Plant Disease 92: 1368-1368.

Pitt JI \& Hocking AD (1997) Aspergillus and related teleomorphs. In Fungi and food spoilage, Springer, Boston, MA, pp. 339-416.

Pitt JI \& Hocking AD (2009) Fungi and food spoilage. Springer, Dordrecht Heidelberg, pp. 313.

Raper KB \& Fennell DI (1965) The genus Aspergillus. pp. 686.

Samson RA \& Varga J (2007) Aspergillus systematics in the genomic era (No. 59). Utrecht: CBS Fungal Biodiversity Centre.

Shittu OB, Adelaja OM, Obuotor TM, Sam-Wobo SO \& Adenaike AS (2016) PCR-Internal Transcribed Spacer (ITS) genes sequencing and phylogenetic analysis of clinical and environmental Aspergillus species associated with HIV-TB co infected patients in a hospital in Abeokuta, southwestern Nigeria. African Health Sciences 16(1): 141-148.

Tamura K \& Nei M (1993) Estimation of the number of nucleotide substitutions in the control region of mitochondrial DNA in humans and chimpanzees. Molecular Biology and Evolution 10: 512-526.

Teertstra WR, Tegelaar M, Dijksterhuis J, Golovina EA, Ohm RA \& Wösten HA (2017) Maturation of conidia on conidiophores of Aspergillus niger. Fungal Genetics and Biology 98: 61-70.

Wösten HAB, Scholtmeijer K \& Vries RP de (2007) Hyperproduction of enzymes by fungi. In: Dijksterhuis J \& Samson RA (eds) Food Mycology: A multifaceted approach to fungi and food. Taylor and Francis, Boca Raton, pp. 183-196. 